\title{
ASSÉDIO, SEXISMO E DESIGUALDADE DE GÊNERO NO AMBIENTE DE TRABALHO
}

Maria Neyrian de Fátima FERNANDES ${ }^{1}$

Emanuele Seicenti de BRITO

Amanda Gonçalves SILVA ${ }^{3}$

Isabelle Barros PICCOLO ${ }^{4}$

Julia Lopes SOUZA

Laura Piccolo CUNHA ${ }^{6}$

Thaís Suemi Varicoda MAKYAMA ${ }^{7}$

ISSUE DOI: $10.21207 / 1983.4225 .615$

\footnotetext{
${ }^{1}$ Graduada em Enfermagem pela Universidade Federal do Rio Grande do Norte (UFRN). Mestre em Enfermagem pela Universidade Federal do Rio Grande do Norte (UFRN). Especialista em Enfermagem do Trabalho pela Universidade Potiguar. Doutoranda em Ciências pela Escola de Enfermagem de Ribeirão Preto da Universidade de São Paulo/Centro Colaborador da OMS para o desenvolvimento da pesquisa em enfermagem (EERP/USP).

${ }^{2}$ Mestre e Doutora em Ciências pela Universidade de São Paulo (USP). Bacharel em Direito pelo Centro Universitário Toledo (UNITOLEDO). Professora Contratada III da Faculdade de Economia, Administração e Ciências Contábeis de Ribeirão Preto da Universidade de São Paulo (FEA-RP/USP). Professora Titular do Centro Universitário Toledo (UNITOLEDO).

${ }^{3}$ Aluna do curso de Administração da Faculdade de Economia, Administração e Ciências Contábeis de Ribeirão Preto da Universidade de São Paulo (FEA-RP/USP).

${ }^{4}$ Aluna do curso de Administração da Faculdade de Economia, Administração e Ciências Contábeis de Ribeirão Preto da Universidade de São Paulo (FEA-RP/USP).

${ }^{5}$ Aluna do curso de Administração da Faculdade de Economia, Administração e Ciências Contábeis de Ribeirão Preto da Universidade de São Paulo (FEA-RP/USP).

${ }^{6}$ Aluna do curso de Administração da Faculdade de Economia, Administração e Ciências Contábeis de Ribeirão Preto da Universidade de São Paulo (FEA-RP/USP).

${ }^{7}$ Aluna do curso de Administração da Faculdade de Economia, Administração e Ciências Contábeis de Ribeirão Preto da Universidade de São Paulo (FEA-RP/USP).
} 


\title{
RESUMO
}

Pode-se notar no ambiente de trabalho a discriminação de gênero de maneira recorrente, variando tanto de formas indiretas quanto diretas. Deve-se ressaltar também que, embora muitas mulheres sejam afetadas pelo patriarcalismo, principalmente no ambiente de trabalho, aquelas pertencentes às classes menos favorecidas e afrodescendentes são as mais vulneráveis. Assim, este artigo objetiva discutir a posição da mulher frente ao mercado de trabalho com maior aprofundamento nos tópicos de ocupação escolha profissional e pressão social-, processo contratual e as dificuldades enfrentadas, diferença salarial e, posteriormente, as discriminações sofridas pela mulher quando já inserida no ambiente profissional, dando maior ênfase à questão do assédio, tanto moral quanto sexual. Trata-se de uma revisão narrativa da literatura. A mulher representa $52 \%$ da população brasileira, mas a sua participação no mercado de trabalho é apenas de $42 \%$. Isso mostra um problema ainda muito presente no ambiente trabalhista, o preconceito com o gênero feminino na hora da contratação pelas empresas. A posição da mulher frente ao mercado de trabalho ainda é permeada de desafios a serem vencidos com a finalidade de equiparar os gêneros.

Palavras-chave: Feminismo. Machismo. Misoginia. Mercado de trabalho. Direito do Trabalho.

\begin{abstract}
It can be noted in the work environment the gender discrimination of recurrent, ranging from both indirect and direct forms. It should also be noted that many of the women are affected by patriarchy, especially without work environment, those belonging to the less favored and Afro-descendant classes are more vulnerable. Thus, this article aims to discuss a position of women facing the labor market with greater depth in the topics of occupation - professional choice and social pressure, contractual process and how difficulties faced, salary difference and etc., such as discrimination suffered by women when already inserted in the professional environment, giving greater emphasis to the issue of harassment, both moral and sexual. This is a narrative review of the literature. A woman represents $52 \%$ of the Brazilian population, but her participation in the labor market is only $42 \%$. This shows a problem still very present in the labor environment, the prejudice with the feminine gender at the time of hiring by the companies. The position of women facing the labor market is still permeated by challenges to be overcome with the aim of equating the genders.
\end{abstract}

Keywords: Feminism. Misogyny. Job market. Labor Law.

\section{INTRODUÇÃO}

A Organização das Nações Unidas (ONU) estabeleceu, na Assembleia do Milênio nos anos 2000, as oito metas do milênio, uma delas foi "Promover a igualdade de gênero e a autonomia das mulheres". Nesse contexto, a partir do tema Discriminação no ambiente de trabalho, este artigo objetiva analisar a situação laboral da mulher.

Indubitavelmente, pode-se notar no ambiente de trabalho a discriminação de gênero de maneira recorrente, variando tanto de formas indiretas quanto diretas, isto é, desde a cultura perpetuada a agressões físicas. Tal discriminação é fruto, em especial, da cultura misógina e patriarcal que foi instaurada ao longo da história da sociedade, a qual 
resultou no negligenciamento do trabalho feminino, taxando a mulher como uma figura frágil e descapacitada.

Em resposta a essa cultura, o movimento feminista originou-se no final do século XIX e propagou-se com maior força no século XX (PINTO, 2009), servindo como suporte para a mulher enfrentar tais discriminações e, assim, conseguir ampliar sua inserção no mercado de trabalho, antes limitada a determinadas profissões em consequência a preconceitos vigentes. Todavia, infelizmente, estes preconceitos continuam disseminados em escala global.

Deve-se ressaltar também que, embora muitas mulheres sejam afetadas pelo patriarcalismo, principalmente no ambiente de trabalho, aquelas pertencentes às classes menos favorecidas e afrodescendentes são as mais vulneráveis. Em decorrência disso, além do machismo naturalizado no contexto social, a falta de informação também contribui para a propagação indireta de ideias machistas, assim como a aceitação, muitas vezes, de situações abusivas e submissas. Foi nessa perspectiva que a socióloga francesa Simone de Beavouir mencionou que a cumplicidade e aceitação dos oprimidos é a razão do fortalecimento do opressor ${ }^{8}$.

Assim, este artigo objetiva discutir a posição da mulher frente ao mercado de trabalho com maior aprofundamento nos tópicos de ocupação -escolha profissional e pressão social-, processo contratual e as dificuldades enfrentadas, diferença salarial e, posteriormente, as discriminações sofridas pela mulher quando já inserida no ambiente profissional, dando maior ênfase à questão do assédio, tanto moral quanto sexual.

\section{MATERIAIS E MÉTODOS}

Trata-se de um estudo de revisão narrativa da literatura baseada em livros, legislações e artigos científicos publicados que abordam a temática relacionada à discriminação sofrida pela mulher no ambiente de trabalho. Como categorias de análises, buscou-se classificar e analisar os estudos de acordo com a particularidade de cada temática identificada no material reunido, prosseguindo com a análise da fundamentação teórica de cada um dos textos.

\footnotetext{
${ }^{8}$ BEAUVOIR, Simone. O segundo sexo. Nova Fronteira, 2014.
} 


\section{RESULTADOS E DISCUSSÃO}

\subsection{A MULHER FRENTE AO MERCADO DE TRABALHO}

Decerto, um ponto que não deve ser esquecido quando se trata do tema "discriminação de gênero no ambiente de trabalho" são as diferentes ocupações exercidas por homens e mulheres no mercado de trabalho.

A questão em pauta tem uma profunda raiz histórica, calcada em perspectivas machistas: historicamente, a mulher tem sido a principal responsável pelas tarefas domésticas, enquanto os homens, por sua vez, cuidavam do campo, dos animais e das guerras. Assim, a cultura machista da atualidade presente no mercado de trabalho fez com que a mulher fosse associada a uma figura frágil que deveria reservar-se às tarefas mais delicadas, domésticas e, quase sempre, submissas aos homens.

Dessa forma, é notório o reflexo da cultura machista na predominância de determinado gênero em certas profissões do mercado de trabalho atual. Afinal, mesmo que, em decorrência das conquistas do movimento feminista, a mulher tenha encontrado espaço nas mais diversas áreas, ainda existe preconceito em segmentos específicos do mercado, como por exemplo, o setor agrícola?

Por outro lado, de acordo com pesquisas, os setores com maior concentração de mão de obra feminina são aqueles na área da Prestação de Serviços para o público, o qual existe ocupações típicas de mulheres assim como professoras, técnicas de enfermagem, nutricionistas, secretárias, recepcionistas. Dada à cultura instaurada, estes cargos e outros ocupados majoritariamente por homens ainda são perpetuados com seus rótulos de gênero ${ }^{10}$.

No Brasil e no mundo a participação feminina na eleição dos representantes políticos é maioria. No entanto, ainda são poucas aquelas que participam da política, apesar de serem ações que podem trazer ótimos resultados, é preciso analisar essa situação com mais profundidade. Exemplo disso é a Câmara dos Deputados, a qual só apresenta 45 mulheres

\footnotetext{
${ }^{9}$ FUNDAÇÃO CARLOS CHAGAS. Lugar das Mulheres no Mercado de Trabalho: Setores de atividade e estrutura ocupacional. Disponível em: <https://www.fcc.org.br/bdmulheres/serie4.php?area=series>. Acesso em: 17 abr. 2017.

${ }^{10}$ FUNDAÇÃO CARLOS CHAGAS. Lugar das Mulheres no Mercado de Trabalho: Setores de atividade e estrutura ocupacional. Disponível em: <https://www.fcc.org.br/bdmulheres/serie4.php?area=series>. Acesso em: 17 abr. 2017.
} 
em contraponto ao número de 468 deputados, segundo dados do site da Câmara de Deputados do Brasil. Todavia, conforme informações do site do Governo Brasil, as mulheres fazem maioria no setor da Administração Pública no cenário nacional, preenchendo 5,5 milhões de postos, num total de 9,5 milhões de cargos disponíveis ${ }^{11}$. Ademais, deve-se ressaltar o sucesso da eleição democrática de uma presidenta para o país, conquista imensurável para o movimento de reconhecimento da mulher no espaço de trabalho e também na vida política.

Quanto ao mercado de trabalho, a inserção da mulher iniciou-se durante a revolução industrial e intensificou-se a partir do século XX. Isso ocorreu não apenas como parte de um movimento social, mas também por necessidade e interesse das empresas que buscavam um maior público consumidor e mão de obra, pois os homens, responsáveis pela renda da família, estavam afastados por conta dos conflitos mundiais ${ }^{12}$.

O Instituto Brasileiro de Geografia e Estatística (IBGE) ${ }^{13}$ registrou que a mulher representa $52 \%$ da população brasileira, mas a sua participação no mercado de trabalho é apenas de $42 \%$, como foi revelado pela Relação Anual de Informações Sociais (RAIS). Isso mostra um problema ainda muito presente no ambiente trabalhista, o preconceito com o gênero feminino na hora da contratação pelas empresas.

Acredita-se que um dos principais motivos dessa discriminação é o direito à licença maternidade, que oferece à mulher um afastamento de 120 ou 180 dias com direito de receber salário integral durante esse tempo. Além disso, acreditam que ela colocará a família em primeiro plano, e não o trabalho, podendo até deixá-lo para cuidar dos filhos. Por conta disso, a contratação da mulher é vista como um prejuízo futuro em potencial.

Um estudo comprovou que as mulheres têm uma desvantagem no processo de recrutamento. O estudo consistia em enviar currículos fictícios e idênticos de dois personagens, Julia Cabot e James Cabot, para 316 escritórios de 147 firmas de direito em 12 cidades estadunidenses. Os resultados mostraram que James foi contratado três vezes mais que Julia,

11 PORTAL BRASIL. Cresce população feminina no mercado de trabalho. Disponível em: <http://www.brasil.gov.br/cidadania-e-justica/2016/03/participacao-feminina-no-mercado-de-trabalho-aumenta-mas-ainda-e-desigual>. Acesso em: 17 abr. 2017

${ }^{12}$ GONSALVES, F. A inserção da mulher no mercado de trabalho: conquista ou imposição social? Disponível em: <http://www.administradores.com.br/artigos/carreira/a-insercao-da-mulher-nomercado-de-trabalho-conquista-ou-imposicao-social/69626/>. Acesso em: 12 abr. 2017.

13 PORTAL BRASIL. Cresce população feminina no mercado de trabalho. Disponível em: <http://www.brasil.gov.br/cidadania-e-justica/2016/03/participacao-feminina-no-mercado-de-trabalho-aumenta-mas-ainda-e-desigual>. Acesso em: 17 abr. 2017 
pois as empresas desacreditavam na experiência de Julia pela simples possibilidade dela vir a ser mãe, mesmo que isso ainda não estivesse nos planos dela ${ }^{14}$.

Esse problema também diminui as possibilidades de haverem líderes femininas, já que cargos com salários altos fazem parte do caminho para um cargo de liderança. De acordo com uma pesquisa feita pelo LinkedIn, a nível global, apenas $25 \%$ das posições de chefia são preenchidas por mulheres ${ }^{15}$.

Não apenas isso, mas muitas candidatas são discriminadas pela sua aparência, sendo desclassificadas no processo de contratação ou até demitidas. Além do mais, a opinião de uma mulher pode ser considerada menos relevante ao se tratar de um assunto que tem maior participação masculina, como esportes, jogos, computação ou política, onde apenas $15 \%$ dos cargos políticos são ocupados por mulheres ${ }^{16}$.

Diante desse contexto, pode-se questionar quais medidas ou estratégias poderiam ser adotadas com a finalidade de reduzir ou erradicar a desigualdade entre os gêneros. Alguns poderiam acreditar que a adoção de cotas para mulheres no trabalho poderia ser uma solução. Todavia, 53\% da população feminina acredita que a discriminação positiva não é algo vantajoso, pois uma candidata deveria ser empregada pelo seu próprio mérito e esforço. As cotas poderiam causar um sentimento de desvalorização nessas mulheres ${ }^{17}$.

Uma possibilidade seria equiparar a licença paternidade à licença maternidade, assim, a responsabilidade de cuidar da criança passaria a ser tanto da mulher quanto do homem, essa equiparação ajudaria, também a aumentar a inserção da mulher no mercado. Esse é o caso da empresa Netflix, que oferece uma licença maternidade e paternidade de um ano com

\footnotetext{
${ }^{14}$ SALEH, N. Mulheres são prejudicadas pela maternidade no mercado de trabalho, aponta estudo. Disponível em <http://revistacrescer.globo.com/Familia/Maes-e-Trabalho/noticia/2017/01/mulheres-sao-prejudicadas-pela-maternidade-no-mercado-de-trabalho-aponta-estudo.html >. Acesso em: 12 abr. 2017.

${ }^{15}$ ISAAC, N. International Women's Day: Celebrating the Progress of Women Leaders in the Workplace. Disponível em: <https://blog.linkedin.com/2017/march/6/international-womens-daytrends-in-women-hiring-and-leadership-linkedin>. Acesso em: 12 abr. 2017.

${ }^{16}$ CAMPOS, E. M. A participação política da mulher. Disponível em <http://www.gazetadopovo.com.br/opiniao/artigos/a-participacao-politica-da-mulher-dr9p81j37ypui18rt3jvwz5n2>. Acesso em: 12 abr. 2017.

${ }^{17}$ ZWIPP, P. Quase metade das mulheres já sofreu preconceito no trabalho. Disponível em: <http://mulher.terra.com.br/noticias/0,,OI5133075-EI16608,00-Quase+metade+das+mulheres+ja+sofreu+preconceito+no+trabalho.html>. Acesso em: 12 abr. 2017.
} 
salário integral ${ }^{18}$. Além disso, a mulher não deveria ser obrigada a declarar à organização seus planos futuros sobre a maternidade.

Apesar de serem ações que podem trazer ótimos resultados, é preciso olhar mais a fundo. Porque $78 \%$ dos homens julgam normal uma mulher deixar o trabalho por conta da família, mas por outro lado, 54\% desprezam e sentem vergonha de pessoas do mesmo sexo que fazem a mesma coisa ${ }^{19}$. A resposta pode estar na cultura brasileira, que avalia como socialmente aceito uma mulher recusar cargos altos por não encarar o trabalho como uma prioridade na vida. Contudo, os homens são muito mais cobrados - e se cobram - a buscar ter uma carreira bem sucedida e rentável.

Não é a totalidade da população masculina que quer priorizar o trabalho e ter que se dedicar mais a ele do que a família, tendo que optar por um dos dois. Mas eles não possuem tanta liberdade social para esse tipo de escolha. A partir do momento que for socialmente aceitável que homens priorizem a vida pessoal às custa da vida profissional, eles se sentirão confortáveis o suficiente para tomar essa decisão. Isso é comprovado na Alemanha, onde muitos homens ficam enquanto as mulheres vão trabalhar e sustentar a família, mas isso só foi possível em decorrência de uma construção e legitimação cultural ${ }^{20}$.

Em suma, a contratação da mulher é um grande desafio na batalha contra a desigualdade de gênero, afinal, para que isso tenha seu fim, é necessário que o machismo seja eliminado das raízes dos valores da sociedade, um processo lento e trabalhoso. Porém, ele é possível e está lentamente abrindo mais portas para a igualdade com as ações que algumas empresas estão tomando. Acredita-se que é uma questão de tempo até que esse preconceito deixe de entravar a vida da população feminina.

Apesar da constante evolução da participação da mulher na sociedade, as disparidades entre os gêneros continuam existindo devido a uma herança cultural misógina. A área profissional é uma das mais

\footnotetext{
${ }^{18}$ REUTERS, D. Netflix adota licença maternidade "ilimitada", sem redução de salário. Disponível em <http://g1.globo.com/economia/negocios/noticia/2015/08/netflix-adota-licenca-maternidadeilimitada-sem-reducao-de-salario.html>. Acesso em: 12 abr. 2017.

${ }^{19}$ TEMÓTEO, A. Machismo e preconceito atrapalham mulheres dentro de empresas, diz pesquisa. Disponível em: <http://www.correiobraziliense.com.br/app/noticia/economia/2013/10/07/internas_economia,392132/machismo-e-preconceito-atrapalham-mulheres-dentro-de-empresas-diz-pesquisa.shtml>. Acesso em: 12 abr. 2017.

${ }^{20}$ NEVES, N. Trabalho, família e aparência definem sucesso para mulheres. Disponível em $<$ http://exame.abril.com.br/carreira/trabalho-familia-e-aparencia-definem-sucesso-para-mulheres/>. Acesso em: 12 abr. 2017.
} 
afetadas, na qual as mulheres sofrem diariamente com problemas de discriminação, que vão desde assédios à depreciação de salários para mesmos cargos ocupados por homens, entre outros.

De acordo com um relatório divulgado pela Organização para a Cooperação e o Desenvolvimento Econômico (OCDE), o Brasil é um dos países com maior discrepância salarial entre homens e mulheres de mesmo nível acadêmico, onde as mulheres ganham, em média, $62 \%$ do que ganham os homens ${ }^{21}$. Em 2014, o IBGE registrou 80\%, o que significa que tal diferença vem diminuindo, porém ainda estamos longe de chegar ao ideal, que seria a igualdade total entre os salários ${ }^{22}$.

No entanto, isso não é um problema apenas do Brasil. Nos Estados Unidos, um estudo revelou que mulheres que trabalhavam em tempo integral recebiam um salário $80 \%$ inferior ao dos homens, o que mostra a seriedade da questão ${ }^{23}$. Em contrapartida, no Reino Unido, onde a defasagem é de 17\%, uma lei trabalhista que entrou em vigor em 2017 , obriga empresas a exporem a diferença salarial entre homens e mulheres, numa tentativa do governo britânico contra a discriminação de gênero ${ }^{24}$.

Enquanto a visão de normalidade machista sobre a desigualdade continuar se propagando, o atraso em comparação a países que tentam ir contra essa ideia, como a Bélgica, que apresenta $3 \%$ de defasagem, tenderá a se agravar, postergando também a evolução do bem-estar mundial ${ }^{25}$.

Uma boa remuneração pode ser vista como um reconhecimento de bom trabalho. Dessa forma, como uma mulher, ao entrar numa empresa, já tem seu salário inferior ao de um homem desenvolvendo a mesma tarefa? O pré-julgamento diz que a mulher tem menor capacidade de desenvolver determinada atividade apenas pelo fato de não ter nascido do sexo masculino? Um profissional deve ser pago pelo seu desempenho, não por

\footnotetext{
${ }^{21}$ VASCO, S. A incômoda questão da igualdade salarial entre gêneros no mercado de trabalho. Disponível em: <http://noticias.universia.com.br/emprego/noticia/2017/03/29/1151086/incomodaquestao-igualdade-salarial-generos-mercado-trabalho.html>. Acesso em: 19 abr. 2017.

${ }^{22}$ CAOLI, C. Mulheres receberam $80 \%$ do salário dos homens em 2014, mostra IBGE. Disponível em: 〈http://glo.bo/1UDp9tm>. Acesso em: 18 abr. 2017.

23 (AAUW. The Simple Truth about the Gender Pay Gap, spring 2017. Disponível em <http://www.aauw.org/aauw_check/pdf_download/show_pdf.php?file=The-Simple-Truth>. Acesso em: 21 abr. 2017.

${ }^{24}$ DUARTE, F. Nova lei obriga empresas a expor diferença entre salários de homens e mulheres no Reino Unido. Disponível em: <http://www.bbc.com/portuguese/geral-39515235>. Acesso em: 21 abr. 2017.

${ }^{25}$ DUARTE, F. Nova lei obriga empresas a expor diferença entre salários de homens e mulheres no Reino Unido. Disponível em: <http://www.bbc.com/portuguese/geral-39515235>. Acesso em: 21 abr. 2017.
} 
seu gênero. Infelizmente, esse preconceito não é refletido apenas na diferença salarial. As mulheres, após inseridas no mercado de trabalho, enfrentam constantemente problemas relacionados ao assédio.

\subsection{ASSÉDIO SOFRIDO PELA MULHER NO AMBIENTE DE TRABALHO}

O assédio moral ocorre quando trabalhadores são expostos a situações humilhantes e constrangedoras que são repetitivas e prolongadas no decorrer da jornada de trabalho e no exercício das atividades laborativas, podendo causar desestabilização da relação do trabalhador com o ambiente e a organização, impelindo-o a desistir do emprego. Analogamente à definição de assédio sexual contida na legislação brasileira, o assédio moral também exige que a atitude em questão seja contínua e intencional. Ainda que majoritariamente seja evidenciado em relações hierárquicas, é possível sua ocorrência em outras esferas laborais ${ }^{26}$.

Todas as classes sociais, sexos, e etnias estão sujeitos ao assédio moral no ambiente de trabalho. No entanto, são as mulheres que lideram as estatísticas sobre o referido fenômeno, correspondendo a $70 \%$ dos assediados, enquanto que para o sexo masculino esse índice decai para apenas $30 \%$, evidenciando a influência da questão de gênero em relação ao tema $^{27}$. A situação pode ser explicada através da contextualização histórica que demonstre o domínio da cultura machista e da sociedade patriarcal sobre as relações humanas juntamente com a influência da identidade social de gênero e construção de estereótipos na sociedade.

Identidade social é um autoconceito proveniente do reconhecimento de pertencimento a um determinado grupo, bem como de seus valores, de forma a auxiliar no entendimento de si próprio e dos outros

\footnotetext{
${ }^{26}$ BARRETO, M. M. Violência, saúde, trabalho: uma jornada de humilhações. São Paulo: EDVC ed. da PUC - São Paulo, 2000.

${ }^{27}$ HIRIGOYEN, M. F. Assédio moral: a violência perversa no cotidiano. $5^{\text {a }}$ ed. Rio de Janeiro: Bertrand Brasil; 2002.
} 
enquanto sociedade 282930 . A identidade social de gênero, analogamente, corresponde à delegação de comportamentos e tarefas referentes aos sexos masculino e feminino, sendo incorporada por meio da convivência social de maneira a ser naturalizada ${ }^{31} 32$. Tal situação molda a visão que se possui do outro e promove a reprodução inconsciente dos comportamentos atribuídos, corroborando para a formação de estereótipos do gênero masculino e feminino ${ }^{34}$.

Inseridas no contexto patriarcal, o estereótipo feminino imposto seria o de ser frágil, dócil, submisso e voltado ao trabalho não remunerado doméstico e familiar, conforme delimitado pela divisão sexual do trabalho. Molda-se então, a visão do homem e da mulher sobre o sexo feminino. Dados nacionais exemplificam a construção social da identidade da mulher no Brasil, $51 \%$ das mulheres e $62 \%$ dos homens acreditam que o homem deve sustentar a família, $75 \%$ das mulheres e $79 \%$ dos homens declararam que quando se tem filhos pequenos, é melhor que o homem trabalhe fora e a mulher fique em casa $^{35} 36$.

A quebra do estereótipo clássico da mulher, propiciada pelas conquistas feministas não é compreendida em sua totalidade pela sociedade ou, tão pouco, é simpática a ela, uma vez que rompe com as estruturas de

${ }^{28}$ LUCAS, A. C. Justiça organizacional de gênero nas empresas: os sentidos atribuídos pelos profissionais de recursos humanos. 2015. Tese (Doutorado em Administração) - Faculdade de Economia, Administração e Contabilidade, Universidade de São Paulo, São Paulo, 2015. doi:10.11606/T.12.2016.tde-13012016-131606. Acesso em: 19 abr. 2018.

${ }^{29}$ TAJFEL, H. Social psychology of intergroup relations. In: Annual Review of Psychology. V.33, n.1, 1982, pp. 1-39.

${ }^{30}$ ASHFORTH, B. E; MAEL, F. Social Identity Theory and the Organization. The Academy of Management Review. v.14, n.1, jan.1989, p. 20.

${ }^{31}$ LUCAS, A. C. Justiça organizacional de gênero nas empresas: os sentidos atribuídos pelos profissionais de recursos humanos. 2015. Tese (Doutorado em Administração) - Faculdade de Economia, Administração e Contabilidade, Universidade de São Paulo, São Paulo, 2015. doi:10.11606/T.12.2016.tde-13012016-131606. Acesso em: 19 abr. 2018.

${ }^{32}$ HOWARD, J. A. Social psychology of identities. In: Annual review of sociology. 200. P. 367-393.

${ }^{33}$ BOURDIEU, P. A dominação masculina. Tradução Maria Helena Kuhner. 5. Ed. Rio de Janeiro: Bertrand Brasil, 2007.

${ }^{34}$ LUCAS, A. C. Justiça organizacional de gênero nas empresas: os sentidos atribuídos pelos profissionais de recursos humanos. 2015. Tese (Doutorado em Administração) - Faculdade de Economia, Administração e Contabilidade, Universidade de São Paulo, São Paulo, 2015. doi:10.11606/T.12.2016.tde-13012016-131606. Acesso em: 19 abr. 2018.

${ }^{35}$ LUCAS, A. C. Justiça organizacional de gênero nas empresas: os sentidos atribuídos pelos profissionais de recursos humanos. 2015. Tese (Doutorado em Administração) - Faculdade de Economia, Administração e Contabilidade, Universidade de São Paulo, São Paulo, 2015. doi:10.11606/T.12.2016.tde-13012016-131606. Acesso em: 19 abr. 2018.

${ }^{36}$ VENTURI, G.; GODINHO, T. (Orgs). Mulheres brasileiras e gênero nos espaços público e privado: uma década de mudanças na opinião pública. São Paulo: Fundação Perseu Abramo/Sesc SP, 2013. 
poder machistas e misóginas tradicionais. Esse fenômeno pode desencadear uma reação hostil por parte da sociedade, em sua maioria homens, como forma de externalizar a aversão ao comportamento feminino moderno, que materializa-se no assédio voltado a mulher nas diversas esferas sociais. No caso tratado, a esfera profissional e o assédio moral são vertentes da ação assediadora, na qual a mulher pode ser vítima em qualquer cargo ocupado, caso seu comportamento seja visto como ameaça.

Um dos caminhos usuais para a prática de assédio é o ataque a características físicas e biológicas da mulher como a possibilidade de gravidez, sendo as mulheres grávidas, com filhos ou casadas notórios alvos, impondo-lhes, por exemplo, a impossibilidade de engravidar, sob o receio da perda de garantia do emprego ${ }^{37}$. Além disso, quando a mulher apresenta um desempenho competente na carreira, atribui-se isso à causas externas, por outro lado, as ações incompetentes são associadas a causas internas e a expressão de emoções é relacionada a instabilidade emocional nas mulheres, enquanto que para o homem é encarada como virtuosa e denominada "sensibilidade masculina"38 3940.

\subsection{CONSEQUÊNCIAS E ALTERNATIVAS PARA OS ASSÉDIOS MORAL E SEXUAL}

O assédio moral para quem sofre, principalmente para a mulher, causa dano à saúde física e mental, levando a um rompimento da relação do indivíduos com seus pares profissionais, núcleo familiar e social, comprometendo, assim, a qualidade de vida em todas as esferas ${ }^{41}$. Um ambiente hostil de trabalho afeta o êxito global da empresa em decorrência

\footnotetext{
${ }^{37}$ SANTOS, L. Assédio moral nas relações de trabalho. Disponível em: <https://www.portaleducacao.com.br/conteudo/artigos/direito/assedio-moral-contra-as-mulheres-no-local-de-trabalho/13776>. Acesso em: 18 abr. 2017.

${ }^{38}$ LUCAS, A. C. Justiça organizacional de gênero nas empresas: os sentidos atribuídos pelos profissionais de recursos humanos. 2015. Tese (Doutorado em Administração) - Faculdade de Economia, Administração e Contabilidade, Universidade de São Paulo, São Paulo, 2015. doi:10.11606/T.12.2016.tde-13012016-131606. Acesso em: 19 abr. 2018.

${ }^{39}$ RAGINS, V.R; WINKEL, D.E. Gender, emotion and power in work relationships. In: Human Resource Management Review. v. 21, n. 4, dez. 2011, pp. 377-393.

${ }^{40}$ CARRIERI, A.P et.al. Gender and work: representations of femininities and masculinities in the view of women Brazilian executives. In: Brazilian Administration Review - Bar. Rio de Janeiro, v.10, n.3, 2013.

${ }^{41}$ SANTOS, L. Assédio moral nas relações de trabalho. Disponível em: <https://www.portaleducacao.com.br/conteudo/artigos/direito/assedio-moral-contra-as-mulheres-no-local-de-trabalho/13776>.

Acesso em: 18 abr. 2017.
} 
do mau desempenho de seus trabalhadores. Somado a isso, a atitude intimidadora corrobora para a manutenção dos estereótipos de gênero e do controle patriarcal sobre a sociedade, pois manifesta-se como um comportamento misógino dentro do ambiente de trabalho.

Outro assédio que ocorre com frequência é o sexual, definido pela Organização Internacional do Trabalho (OIT) como ações indesejadas que se caracterizem como uma circunstância para manter o emprego, exercer influência, insinuações, contatos indesejados que podem ser postos como uma condição para a manutenção do emprego; interferir na promoção da carreira; afetar o rendimento profissional; prejudicar o rendimento profissional, humilhar, insultar ou intimidar o assediado, bem como ameaçar e fazer com que as vítimas cedam por medo de denunciar o abuso; e oferta de oportunidades profissionais que desfavoreçam ou sejam possibilidade de troca para a vítima (Tribunal Regional do Trabalho da $10^{\mathrm{a}}$ Região, 2013).

Homens e mulheres são alvos de assédio sexual no trabalho, não obstante esta perseguição é muito mais frequente sobre o público feminino, $52 \%$ das mulheres economicamente ativas já foram assediadas sexualmente conforme dados da OIT. Uma possível justificativa para tamanha diferença seria a cultura do machismo na qual a figura feminina é vista como um objeto inferior ao homem ${ }^{42}$.

O assédio sexual se manifesta de duas formas, uma forma é a chantagem quando o superior hierárquico exige que o subordinado pratique algum ato de cunho sexual contra a vontade deste empregado, sob a pressão da perda de sua ocupação ou mesmo de seus privilégios. A outra modalidade se dá por intimidação em que esse superior pratica o hábito de ofender, tocar, mexer e provocar a vítima, humilhando-a. Ambos podem ocorrer de maneira vertical ou horizontal frequentemente dentro da organização, sendo mais comum verticalmente. Flertar no trabalho é algo permitido, entretanto caso este fato ao invés de obter a reciprocidade gere um incômodo no próximo há algo errado e grave que precisa ser solucionado.

Este é um tema que persiste há tempos na sociedade, tal assédio confronta o direito de liberdade sexual do indivíduo e no ambiente de trabalho se faz presente na maior parte dos casos como maneira de

\footnotetext{
${ }^{42}$ SOUZA, M. Vida no trabalho. Disponível em <https://economia.uol.com.br/empregos-e-carreiras/noticias/redacao/2013/03/08/52-das-mulheres-ja-sofreram-assedio-no-trabalho-falta-de-provas-dificulta-condenacoes.htm>. Acesso em: 18 abr. 2017.
} 
chantagem, manipulação e aproveitamento em que uma pessoa tenta usar de sua posição influente para obter vantagens em relação a outra.

As causas para esta situação são abundantes e podem estar relacionadas com o jogo de poder entre determinadas ocupações dentro da empresa, o sentimento de ameaça que o indivíduo desperta, a própria fisionomia, beleza exagerada ou corpo exuberante. A dificuldade de lidar com o outro, de admirar suas conquistas provocando a inveja e a tentativa de barrar o crescimento profissional e pessoal do funcionário dentro do trabalho.

Exemplificando a conduta antiética na esfera profissional situase o caso divulgado em Março de 2017 do ator José Mayer, funcionário da rede globo, que assediou uma colega de trabalho dirigindo elogios abusivos e tocando suas partes íntimas. Outro caso polêmico foi o escândalo sexual envolvendo o ex presidente dos Estados Unidos, Bill Clinton e sua estagiária no qual o governante foi acusado de ter relações sexuais com esta.

É importante ressaltar que o indivíduo submetido a uma situação abusiva pode desenvolver danos psicológicos em decorrência da humilhação e dos atos praticados pelo agressor, tornando-se vulnerável afetando sua autoestima e sua maneira de enfrentar os fatos. Além de consequências como a demissão, ao afetar a saúde mental do indivíduo doenças como a depressão, o aumento do estresse, das mágoas e dores surgem, podendo levar a atos extremos, como o suicídio. Homens e mulheres costumam reagir de maneira diferente em relação a isto, enquanto eles preferem o isolamento e o sofrimento em silêncio pelo sentimento de culpa e vergonha, elas são mais sentimentais apresentando alterações na memória, tremores, insônia, distúrbios e pensamentos repetitivos e culpa.

Nessas situações, podem ser considerados avanços, a alteração das leis vigentes, bem como da penalidade atribuída aos agressores, como ocorre com a legislação brasileira, na qual são asseguradas não apenas a reparação da vítima, mas também a sua possibilidade de relutar as ofensivas assediadoras, não sendo obrigada a permanecer em seu emprego apenas pela força do contrato de trabalho, como previsto no art. 483 e na $\mathrm{CLT}^{43}$. Visando amenizar e sanar a questão assediadora em casos horizontais, uma alternativa seria a responsabilização do empregador, uma

\footnotetext{
${ }^{43}$ TRINDADE, Raquel Guimarães da. O assédio moral como prática discriminatória contra a mulher nas relações de trabalho. In: Âmbito Jurídico, Rio Grande, XVIII, n. 140, set 2015. Disponível em: $<$ http://www.ambitojuridico.com.br/site/index.php?n_link=revista_artigos_leitura\&artigo_id=16371\&revista_caderno=25>. Acesso em jan 2018.
} 
vez que sua função também é o zelo por um ambiente produtivo saudável e livre de assédio, como previsto pelo art.247.2 do Código de Trabalho canadense ${ }^{44}$.

Dentre as Políticas de Combate à Discriminação de Gênero no Ambiente de Trabalho, a Organização das Nações Unidas (ONU) apregoa os princípios de empoderamento das mulheres como o tratamento de forma justa no ambiente de trabalho, estabelecimento de liderança corporativa de alto nível para promover a igualdade de gêneros dentre outros que buscam fortalecer o papel das mulheres no ambiente de trabalho, objetivando apoiar ações das empresas que favoreçam a equidade de gênero com forte influência no setor privado no Brasil ${ }^{45}$.

Diante desse contexto, o local de trabalho deve ser um ambiente leve e agradável, com relações interpessoais saudáveis, sem intrigas, brincadeiras de mal gosto e quando houver alguma situação de assédio, a vítima deverá ser apoiada e consolada. O grande problema do Brasil e do mundo é que apesar da existência de leis e artigos combatendo o assédio, a eficiência não é satisfatória e em alguns casos é muito difícil provar as ações. Outra barreira que ainda precisa ser superada é o medo e angústia da vítima em admitir que está sofrendo abusos e que precisa de ajuda ou mesmo o temor de denunciar o agressor e enfrentar consequências ainda maiores.

\section{CONCLUSÃO}

A posição da mulher frente ao mercado de trabalho ainda é permeada de desafios a serem vencidos com a finalidade de equiparar os gêneros. As diferenças salariais, de tratamento e assédios ainda são predominantes nas mulheres. Ainda existem setores específicos de trabalho em que as mulheres têm espaço reduzido e sua representação política no país não condiz com o percentual da população feminina do país. As características inerentes ao gênero feminino e os direitos adquiridos ao longo dos tempos não podem ser entraves no processo de contratação ou

\footnotetext{
${ }^{44}$ CANADÁ. Code canadien du travail (L.R.C. (1985), ch. L-2). Disponível em: <http://laws-lois.justice.gc.ca/fra/lois/l-2/index.html?pedisable=true>. Acesso em: 18 abr. 2017.

${ }^{45}$ ORGANIZAÇÃO DAS NAÇÕES UNIDAS (ONU). Princípios de empoderamento das mulheres. Disponível em: <http://www.onumulheres.org.br/referencias/principios-de-empoderamento-das-mulheres/>. Acesso em: 03 de out. 2017.
} 
ascensão profissional. Assim, para promover uma sociedade mais justa para o gênero, políticas públicas de âmbito mundial e nacional estão sendo implementadas com a finalidade de reduzir tais disparidades e empoderar a força feminina no mundo do trabalho.

Percebe-se que a cultura patriarcal afeta negativamente a força de trabalho feminina, seu desempenho e produtividade. Desta forma, a principal contribuição deste estudo é convocar a sociedade a compreender que as questões de baixos salários, assédios, participação no trabalho e baixa representatividade política possuem raízes históricas e culturais que necessitam ser revistas e readequadas para uma realidade em constante transformação

\section{REFERÊNCIAS}

AAUW. The Simple Truth about the Gender Pay Gap, spring 2017. Disponível em <http://www.aauw.org/aauw_check/pdf_download/show_pdf.php?file=The-Simple-Truth>. Acesso em: 21 abr. 2017.

ASHFORTH, B. E; MAEL, F. Social Identity Theory and the Organization. The Academy of Management Review. v.14, n.1, jan.1989, p. 20.

BARRETO, M. M. Violência, saúde, trabalho: uma jornada de humilhações. São Paulo: EDVC ed. da PUC - São Paulo, 2000.

BOURDIEU, P. A dominação masculina. Tradução Maria Helena Kuhner. 5. Ed. Rio de Janeiro: Bertrand Brasil, 2007.

CAMPOS, E. M. A participação política da mulher. Disponível em $<$ http://www.gazetadopovo.com.br/opiniao/artigos/a-participacao-politica-da-mulherdr9p81j37ypui18rt3jwwz5n2>. Acesso em: 12 abr. 2017.

CANADÁ. Code canadien du travail (L.R.C. (1985), ch. L-2). Disponível em: <http://lawslois.justice.gc.ca/fra/lois/l-2/index.html?pedisable=true>. Acesso em: 18 abr. 2017.

CAOLI, C. Mulheres receberam $80 \%$ do salário dos homens em 2014, mostra IBGE.

Disponível em: 〈http://glo.bo/1UDp9tm>. Acesso em: 18 abr. 2017.

CARRIERI, A.P et.al. Gender and work: representations of femininities and masculinities in the view of women Brazilian executives. In: Brazilian Administration Review - Bar. Rio de Janeiro, v.10, n.3, 2013.

CORRÊA, A. M. H.; CARRIERI, A . DE P. Percurso semântico do assédio moral na Trajetória Profissional de Mulheres Gerentes. In: Revista de Administração de Empresas-RAE. V.47, N.1, 2007, PP. 28-32.

BEAUVOIR, Simone. O segundo sexo. Nova Fronteira, 2014. 
DEAUX, K. From individual differences to social categories. Analysis of a decade's research pn gender. In: American Psychologyst. V.39, n.2, 1984, p. 105.

DUARTE, F. Nova lei obriga empresas a expor diferença entre salários de homens e mulheres no Reino Unido. Disponível em: 〈http://www.bbc.com/portuguese/geral-39515235>. Acesso em: 21 abr. 2017.

DUTRA, E. Os desafios das mulheres no mercado de trabalho. Disponível em:

<http://exame.abril.com.br/carreira/os-desafios-das-mulheres-no-mercado-de-trabalho/>. Acesso em: 12 abr. 2017.

FUNDAÇÃO CARLOS CHAGAS. Lugar das Mulheres no Mercado de Trabalho: Setores de atividade e estrutura ocupacional. Disponível em: <https://www.fcc.org.br/bdmulheres/serie4.php?area=series>. Acesso em: 17 abr. 2017.

GONSALVES, F. A inserção da mulher no mercado de trabalho: conquista ou imposição social? Disponível em: <http://www.administradores.com.br/artigos/carreira/a-insercao-da-mulher-nomercado-de-trabalho-conquista-ou-imposicao-social/69626/>. Acesso em: 12 abr. 2017.

HIRIGOYEN, M. F. Assédio moral: a violência perversa no cotidiano. $5^{\mathrm{a}}$ ed. Rio de Janeiro: Bertrand Brasil; 2002.

HOWARD, J. A. Social psychology of identities. In: Annual review of sociology. 200. P. 367-393.

ISAAC, N. International Women's Day: Celebrating the Progress of Women Leaders in the Workplace. Disponível em: <https://blog.linkedin.com/2017/march/6/international-womens-daytrends-in-women-hiring-and-leadership-linkedin>. Acesso em: 12 abr. 2017.

LUCAS, A. C. Justiça organizacional de gênero nas empresas: os sentidos atribuídos pelos profissionais de recursos humanos. 2015. Tese (Doutorado em Administração) - Faculdade de Economia, Administração e Contabilidade, Universidade de São Paulo, São Paulo, 2015. doi:10.11606/T.12.2016.tde-13012016-131606. Acesso em: 19 abr. 2018.

NEVES, N. Trabalho, família e aparência definem sucesso para mulheres. Disponível em <http://exame.abril.com.br/carreira/trabalho-familia-e-aparencia-definem-sucesso-para-mulheres/>. Acesso em: 12 abr. 2017.

ORGANIZAÇÃO DAS NAÇÕES UNIDAS (ONU). Princípios de empoderamento das mulheres. Disponível em: <http://www.onumulheres.org.br/referencias/principios-de-empoderamento-dasmulheres/>. Acesso em: 03 de out. 2017.

PINTO, C.R.J. Feminismo, história e poder. Rev. Sociol. Polit. v. 18, n. 36, p. 15-23, 2010 .

PORTAL BRASIL. Cresce população feminina no mercado de trabalho. Disponível em: <http://www.brasil.gov.br/cidadania-e-justica/2016/03/participacao-feminina-no-mercado-detrabalho-aumenta-mas-ainda-e-desigual>. Acesso em: 17 abr. 2017

RAGINS, V.R; WINKEL, D.E. Gender, emotion and power in work relationships. In: Human Resource Management Review. v. 21, n. 4, dez. 2011, pp. 377-393.

REUTERS, D. Netflix adota licença maternidade "ilimitada", sem redução de salário. Disponível em <http://g1.globo.com/economia/negocios/noticia/2015/08/netflix-adota-licenca-maternidadeilimitada-sem-reducao-de-salario.html>. Acesso em: 12 abr. 2017. 
SALEH, N. Mulheres são prejudicadas pela maternidade no mercado de trabalho, aponta estudo. Disponível em <http://revistacrescer.globo.com/Familia/Maes-e-Trabalho/noticia/2017/01/mulheressao-prejudicadas-pela-maternidade-no-mercado-de-trabalho-aponta-estudo.html>. Acesso em: $12 \mathrm{abr}$. 2017.

SANTOS, L. Assédio moral nas relações de trabalho. Disponível em: $<$ https://www.portaleducacao.com.br/conteudo/artigos/direito/assedio-moral-contra-as-mulheres-nolocal-de-trabalho/13776>. Acesso em: 18 abr. 2017.

SOUZA, M. Vida no trabalho. Disponível em <https://economia.uol.com.br/empregos-ecarreiras/noticias/redacao/2013/03/08/52-das-mulheres-ja-sofreram-assedio-no-trabalho-falta-deprovas-dificulta-condenacoes.htm>. Acesso em: 18 abr. 2017.

TAJFEL, H. Social psychology of intergroup relations. In: Annual Review of Psychology. V.33, n.1, 1982, pp. 1-39.

TEMÓTEO, A. Machismo e preconceito atrapalham mulheres dentro de empresas, diz pesquisa. Disponível em:

<http://www.correiobraziliense.com.br/app/noticia/economia/2013/10/07/internas_economia,392132/ machismo-e-preconceito-atrapalham-mulheres-dentro-de-empresas-diz-pesquisa.shtml >. Acesso em: 12 abr. 2017.

TRINDADE, Raquel Guimarães da. O assédio moral como prática discriminatória contra a mulher nas relações de trabalho. In: Âmbito Jurídico, Rio Grande, XVIII, n. 140, set 2015. Disponível em: <http://www.ambito-juridico.com.br/site/index.php?n_link=revista_artigos_leitura\&artigo_id=16371\&revista_caderno=25>. Acesso em jan 2018.

VASCO, S. A incômoda questão da igualdade salarial entre gêneros no mercado de trabalho. Disponível em: <http://noticias.universia.com.br/emprego/noticia/2017/03/29/1151086/incomodaquestao-igualdade-salarial-generos-mercado-trabalho.html>. Acesso em: 19 abr. 2017.

VENTURI, G.; GODINHO, T. (Orgs). Mulheres brasileiras e gênero nos espaços público e privado: uma década de mudanças na opinião pública. São Paulo: Fundação Perseu Abramo/Sesc SP, 2013.

ZWIPP, P. Quase metade das mulheres já sofreu preconceito no trabalho. Disponível em: <http://mulher.terra.com.br/noticias/0,,OI5133075-EI16608,00-

Quase+metade+das+mulheres+ja+sofreu+preconceito+no+trabalho.html>. Acesso em: 12 abr. 2017. 